\title{
Proposal and psychometric validation of the Severe Acute Respiratory Syndrome - Coronavirus-2 Fear Scale (SCoV-2-FS)
}

Sérgio Monteiro de Almeida ( $\square$ sergio.ma@ufpr.br)

Universidade Federal do Paraná, Brasil

Clara Putini Villibor

Universidade Federal do Paraná, Brasil

Suzana Carstensen

Universidade Federal do Paraná, Brasil

Ricardo Rasmussen Petterle

Universidade Federal do Paraná, Brasil

\section{Research Article}

Keywords: COVID-19, Fear, Psychological distress, Life satisfaction, Scale, SARS-CoV-2

Posted Date: July 27th, 2020

DOI: https://doi.org/10.21203/rs.3.rs-48227/v1

License: (c) (i) This work is licensed under a Creative Commons Attribution 4.0 International License. Read Full License 


\section{Abstract}

Background: The emergence of severe acute respiratory syndrome coronavirus 2 (SARS-CoV-2) pandemic has created an unprecedented global health, economic, and social challenges, generating fear. Fear can cause a range of physical and psychological disorders including depression, anxiety, and panic. Leading to lower social isolation and adherence to security measures, consequently increasing infection risk. The objective was to validate an 11-item unidimensional fear scale to identify and assess the severity of the fear of SARS-CoV-2.

Methods: This was a cross-sectional study conducted through an online survey questionnaire. The sample included the Brazilian general population, randomly recruited by social networking platforms, during the pandemic. Participants aged $\geq 18$ were included. A self-applicable fear scale named as the SARS-CoV-2 Fear Scale (SCoV-2-FS), comprising 11 questions addressing the fear of SARS-CoV-2 infection in performing daily activities was validated. The reliability and validity of the SCoV-2-FS were psychometrically evaluated using reliability measures and confirmatory factor analysis (CFA). The sample comprised 1332 Brazilian participants.

Results: Cronbach's a was 0.9 , indicating very good internal reliability. The results of the CFA showed that the unidimensional factor structure of the SCoV-2-FS fitted well with the data.

Limitations: The sampling method could have introduced selection bias in terms of socio-demographics.

Conclusion: The SCoV-2-FS is a valid and reliable tool with robust psychometric properties, useful for assessing the psychological impact of fear due to COVID-19. Clinical relevance: The development of a scale may assist in the development of measures to control mental health disorders resulting from fear during and after the pandemic.

\section{Introduction}

The severe acute respiratory syndrome coronavirus 2 (SARS-CoV-2), identified in December 2019, is highly contagious and its incidence has increased exponentially (Dong et al., 2020). Its widespread transmission was recognized by the World Health Organization (WHO) as a pandemic (Huang et al., 2020). The public health challenges due to the SARS-CoV-2 pandemic are unprecedented. It is considered the largest and most serious pandemic since the influenza pandemic in the first half of the $20^{\text {th }}$ century (Taubenberger and Morens, 2006). The SARS-CoV-2 cases exceeded 11 million on July 3rd, 2020 globally. Several uncertainties related to the SARS-CoV-2 and its clinical syndrome (COVID-19) has impacted health, economic, social, and political sectors. This has impacted the population's daily life and mental health (Thakur and Jain, 2020). 
The pandemic restores the ancestral fear of humans toward pests and infectious diseases (Riva et al., 2014), and exposes the fragility of the human beings and the economic, social, and cultural systems developed by humans and their beliefs about it. All caused by an invisible and unknown agent. The SARS-CoV-2 pandemic results in distress and fear in the population due to several aspects (Ahorsu et al., 2020; Rajkumar, 2020). The pandemic is caused by a newly identified highly contagious virus, spreading rapidly to all continents. The SARS-CoV-2 causes a complex and severe syndrome (COVID-19), with the predominant involvement of the respiratory system, along with the heart, kidneys, coagulation, and brain being involved (Ellul et al., 2020; Prezioso et al., 2020). Its pathophysiology is not completely known. The lack of specific treatment or vaccine results in high and long duration of intensive care unities occupation, and high mortality, which leads to the collapse of the health system even in rich countries. Additionally, there is a large impact in the community with change in daily routine activities, implementing social distancing measures, such as quarantine, social isolation, use of masks, lockdown, home office, cancellation of concerts and sporting events, with closure of museums, stores, shopping centers, schools and universities. The great economic impact, with an abrupt increase in unemployment and bankruptcy, has resulted in the greatest and most rapid change in the employment sector ever recorded (Thakur and Jain, 2020). There are discordant opinions by political and health directors as well as the WHO, concerning social isolation or use of experimental drugs for treatment (The Lancet, 2020). The precariousness of the health systems became clearer, with the spread of the disease to small cities inside the country. Some characteristics are specific to our time, as the possibility to follow the news in real time, associated with the increasing number of fake news items. Resulting in misinformation and infodemic, i.e. an excessive amount of information such that finding a solution is would be more difficult and misinformation (Zarocostas, 2020). Besides this, there is uncertainty in the future and a feeling of post apocalypses, i.e. the feeling of a different normal, a new normal, suggesting that all what was done before the pandemic would not matter in the future.

Fear is a noun that means an unpleasant, often strong emotion caused by anticipation or awareness of danger. It is a kind of disturbance when faced with the idea that one is exposed to some kind of danger, which may be real or not. It can also be understood as a state of apprehension, of attention, waiting for something bad to happen (Merriam-Webster dictionary, 2020). In addition to the definitions of the word, fear is a sensation linked to a state in which the organism puts itself on alert, facing something that is believed to be a threat. Fear is an alert extremely important for human survival; without any fear a person can expose himself to extremely dangerous situations, risking his own life, without measuring the possible tragic consequences of his actions.

There are a limited number of studies regarding the mental health impact of SARS-CoV-2 infection impact on mental health (Mamun and Griffiths, 2020; Schimmenti et al., 2020). It is crucial to understand the impact of the pandemic on people's mental health (Xiang, 2020). However, there is no available measuring tool to evaluate the fear of SARS-CoV-2. With an instrument to assess the fear of SARS-CoV-2, it would be possible to understand the psychological impact of SARS-CoV-2 and to develop psychological interventions to help people cope with the fear caused by the pandemic. 
The objective of this study was to validate a brief scale for assessing the fear of the SARS-CoV-2 pandemic.

\section{Methods}

This was a cross-sectional study conducted using an online survey questionnaire from April 30 to June 9 , 2020. For this purpose, a specific questionnaire was created at the www. Google forms.com, and a quick response (QR) code was designed specifically for the link to the online survey. The Setor de Ciencias da Saude da Universidade Federal do Paraná (UFPR), Brazil, review board approved the study. The online survey link was distributed randomly in personal and professional networks (communities and web groups) and email. The response to the forms was received online. Participation in the survey was voluntary and completely anonymous, without the possibility of anonymity break. The electronic form could be accessed only once by each google email address.

\section{Assessment of fear}

Development of the scale Relevant and possible items, which could expose the person to risk of infection by SARS-CoV-2 on daily life necessities and activities were identified by two authors (SMA and CPV). After removing items with similar content or not specifically related to the construct "fear", 15 items were selected; on a second review by the same two authors four items were excluded. This resulted in the 11 items scale, which was circulated on-line.Initial assessment of scaleParticipants from the same institution of the researchers and self-identified as responders, answered the online form on the initial day of circulation [06 women and 01 man; median (IQR): age $51.00(42.50 ; 55.00)$ years; years of education $22.00(18.00 ; 23.50)]$. They were asked to obtain initial assessment of the scale, as if there were any problems in understanding the items themselves; their thoughts about the scale items, accessibility to the form through the link or QR code, and time to answer the form, which was reported one to two minutes. These participants indicated no changes. The authors propose an English version of the SCoV-2-FS. For the English version of the SCoV-2-FS, forward-backward translation method was applied (Table 1). The items were translated into English by a Portuguese native speaker fluent in English, reviewed and corrected by an English native speaker, further translated back into Portuguese by another bilingual Portuguese native speaker fluent in English professional who had not seen the Portuguese version of the SCoV-2-FS (back translation). SARS-CoV-2 Fear Scale (SCoV-2-FS)The fear scale, which was titled SARSCoV-2 Fear Scale (SCoV-2-FS), comprised 11 closed-ended questions, in Portuguese, focused on the fear of the risk of infection with SARS-CoV-2, on daily life necessities and activities, such as, going out on the street, going to the market, pharmacy, hospital, using an elevator, contact with other people, and public transport. Fear about being infected with SARS-CoV-2, in person or someone close. Fear to die of complications of SARS-CoV-2, in person or someone close (Table 1).

The participants indicated their level of fear using a five-item Likert-type scale, which was used to measure the level of fear in the study. The degree of fear was reflected using 1-5 point, with higher 
scores indicating greater fear. Details of the scale are as follows: 1 , no fear; 2 , mild; 3 , moderate; 4, a lot; and 5 , severe. A total score was calculated by adding up each item score (range, from 11 to 55 ).

\section{Demographic data and risk factors}

Participants were stimulated to report birth date, gender, years of education, religion, city, state, country, and ZIP code. Identification of risk factors for poor prognosis of COVID-19 or SARS-CoV-2 infection (yes/no): necessity to go to work, health workers, and existence of comorbidities (chronic diseases).

\section{Participants}

The target population was the general Brazilian population. Participants were randomly recruited online in personal, professional networks, and emails. The participant was asked to disclose the electronic questionnaire among their contacts and social networks (snowball sampling strategy). Inclusion criteria: participants aged 18 years or above, literate, fluent in Portuguese, and familiar with the use of social networking. Exclusion criteria: responses from participants under 18; incomplete responses, or participants from other counties were excluded.

\section{Statistical analyses}

Categorical variables were described by frequency of distribution $(n, \%)$, while continuous variables were described by median (IQR). Analysis of the psychometric properties of the SCoV-2-FS was described by Skewness and Kurtosis to check for asymmetry and kurtosis were in the range from -1 to +1 in the case of normal univariate data distribution. To check if the normal distribution model fits the observations, the Shapiro-Wilk normality test was used.

\section{Reliability (internal consistency)}

Reliability (i.e. internal consistency) of the SCoV-2-FS was examined by Composite reliability (cutoff $\geq 0.7$; Netemeyer et al., 2003); Cronbach's a (cutoff $\geq 0.9$; Barret and Kline, 1981), Guttmann $\otimes 6$ (G6, smc), McDonald's w (0 .70; Graham, 2006).

To confirm the factor structure (model fit), the SCoV-2-FS was examined with the Confirmatory factor analysis (CFA; Kline, 2015). Several indices were used to assess model fit, including standardized root mean square residual (SRMR, cutoff $\leq 0.08$ ), comparative fit index ( $\mathrm{CFI}$, cutoff $\geq 0.9$ ), goodness-of-fit index (GFI, cutoff $\geq 0.8$; Doll et al.,1994); normed of fit index ( $N F I$, cutoff $\geq 0.9$ ), and standardized factor loading. To evaluate how each individual item affects the reliability of the scale, the measurements were calculated on the overall score and removing each of the items of the scale. The correlation coefficients between each item of the SCoV-2-FS were calculated with a standardized variance/covariance matrix (correlation matrix, using Pearson's correlation coefficient). Statistical significance was considered as $p<$ 0.05 . 
The cutoff of SCoV-2-FS was calculated by the confidence interval using the Z statistic, determined by confidence level $(Z=1.96)$, and sample mean to generate an interval estimate of the population mean.

The analysis was carried out using the statistical package R software (R Core Team, 2019, Vienna, Austria) version 3.6.1.

\section{Results}

A total of 1368 persons answered the electronic form, and persons under 18 years of age $(n=10)$, and answers from other countries $(n=26)$ were excluded. The final sample comprised 1332 participants, with a ratio of number of participants to number of the scale items of 121:1 (recommended ratio 5:1; Floyd and Widaman, 1995).

Age, median (IQR), $36.29(26.74 ; 49.95)$ years, were distributed in a non-normal way, skewness, and excess kurtosis a4 (0.509 and -0.789 , respectively; Suppl. Figure $1 \mathrm{~A})$; Shapiro-Wilk test, $p<0.05, W=0.944$, $95 \%$ critical value accepted range, CVAR $[0.998 ; 1.000]$. There was no relation between the total SCoV-2FS score and age ( $r s=0.017, p=0.539)$. Years of education, median (IQR), $18.00(15.00 ; 20.00)$ years, distributed in a non-normal way; skewness and kurtosis a4 (0.817 and 2.378, respectively; Suppl. Figure 1B), Shapiro-Wilk test, $p<0.05, W=0.939 .95 \%$ CVAR [0.998; 1.000]; distribution by sex: female, 974 (73.12\%); male 353 (26.50\%); other 5 (0.36\%). The forms were received from all the Brazilian geographic regions, mainly from South $872(65.47 \%)$ (Figure 1).

\section{Psychometric analysis of the SCoV-2-FS}

The distribution of the 11 SCoV-2-FS items, no missing data, and most items were distributed asymmetrically, with the highest frequencies in the highest values (Figure 2). As for asymmetry and kurtosis, most of the items were distributed in a non-normal way, as the items did not fall within the range of \pm 1 (Table 2). Using the Shapiro-Wilk normality test, all items were distributed in a non-normal way ( $p<$ .0001). Moreover, the SCoV-2-FS appeared to have a unidimensional structure.

The metrics calculated to analyze the reliability (i.e., internal consistency) SCoV-2-FS items proved to be highly reliable. For the total SCoV-2-FS score, Cronbach's a was 0.930 and McDonald's $\omega$ was 0.950 , indicating very good internal reliability. Reliability could not be improved by removing any items (Table 3 ). The results of the CFA showed that SRMR 0.08; CFI 0.90; GFI 0.786; NFI 0.090, all were within the acceptable limits for the total score of the SCoV-2-FS, indicating the structure of the SCoV-2-FS fitted well with the data (Table 3).

There was a positive relationship between all items (Table 4), $(\min =0.387, \max =0.876$; all items are statistically significant for $p<0.001$, polychoric correlations). These results indicate that FCV-19S presented a good fit to the data. The cutoff of the SCoV-2-FS was $41.345(Z=1.96)$ (Table 2).

\section{Discussion}


The psychometric analysis of the SCoV-2-FS showed a strong internal consistency (demonstrated by Cronbach's $a$ and McDonald's $\omega$ results). The main advantage of McDonald's $\omega$, compared to Cronbach's $a$, is the strength of association between items and constructs as well as item-specific measurement errors. Thus, McDonald's $\omega$ provides more realistic estimates of the true reliability of scale; (b) acceptable construct validity (demonstrated by CFA); (c) unidimensional structure (demonstrated by the CFA); (d) The SCoV-2-FS can be used in the general population irrespective of age, as this study demonstrated that the fear response was not significantly influenced by the participant's age, suggesting that facing a global pandemic, people of all age groups feel threatened and answer similarly (Sakib et al., 2020).

Fear is an adaptive animal defense mechanism that is fundamental for survival and involves several biological processes of preparation for a response to potentially threatening events. Fear in human triggers reactions (mostly psychological) for preparation to respond to a threatening agent. However, when it is chronic or disproportionate, it becomes harmful and can be a key component in the development of various psychiatric disorders (Garcia, 2017). It can cause sleep, appetite or substance use disorders, depression, anxiety, panic, or even increase of suicide rates in susceptible people (Rajkumar, 2020; McIntyre and Lee, 2020). In a pandemic, fear increases anxiety and stress levels in healthy individuals and intensifies the symptoms of those with preexisting psychiatric disorders (Shigemura et al., 2020). Besides this, fear can result in prejudice against sick people, people recovered from the COVID19 , or even health professionals. The stigma can lead people to refute early symptoms, contributing to the disease remaining undetected, facilitating its spread. Another result of the fear can be the denial of the pandemic. Denial or abnegation (German: Verneinung) is an unconscious defense mechanism that involves a refusal to accept reality. When the situation is too much to handle, the person may respond by refusing to perceive it or by denying that it exists. This can be implicit in declarations as COVID-19 being a simple flu; this does not exist, or it is an elderly disease and does not affect young and athletic people. Denial can result in lapses in security and social isolation measures, increasing the risk of infection. Denial is the most detrimental to public health; it is especially catastrophic when policy makers and government officials are in a state of denial (The Lancet, 2020). Additionally, fear itself can be contagious (Epstein, 2009). Consequently, reducing fear and discrimination among individuals can be important in controlling transmission.

The construct validity of the SCov-2-FS was high, as there was agreement between the theoretical concept and the specific measurement of fear during the SARS-CoV-2 pandemic. There was focus on the theoretical dimensions of the construct; the SCoV-2-FS intents to explore specifically the feeling of fear of daily life activities during the SARS-CoV-2 pandemic; the scale does not explore symptoms of fear, as these are usually superimposed with those of anxiety or depression (Harper et al., 2020). SCov-2-FS did not include other aspects, such as depression or anxiety, which could lead to inappropriate diagnosis (Slocum-Gori and Zumbo, 2011). Symptoms of fear were explored by the Fear of COVID-19 Scale (FCV19S; Ahorsu et al., 2020). Many of the items in the FCV-19S scale are pertinent to anxiety, with a strong relationship between the FCV-19S and Diagnostic and Statistical Manual of Mental Disorders (DSM)based measures of anxiety (Ahorsu et al., 2020; Sakib et al., 2020; Harper et al., 2020; Alyami et al., 2020; Bitan et al., 2020; Satici et al., 2020; Soraci et al., 2020). Due to the cross-sectional nature of these 
studies, it was unclear as to whether being depressed heightens the fear concerning COVID-19 or viceversa, or both (Ahorsu et al., 2020; Harper et al., 2020). Fear and anxiety are behaviorally and neuroendocrinologically distinct responses (Garcia, 2017).

The main value of this study was that it was conducted using a large sample of participants with varying ages from the general Brazilian population encompassing participants from all the regions, therefore with national representativeness. However, the present study has some limitations. (a) Fear is a real feeling, although it is subjective and difficult to quantify. For the SCoV-2-FS, a numeric rating scale was used. The numeric rating scale has been reported to have good reliability, validity, and sensitivity (Becker et al., 2020). (b) the nature of the self-report cannot exclude the possibility that respondents provided responses affected by social desirability factors, memory recall, and other method biases. (c) No formal diagnoses of mood disorders, such as anxiety or depression, or previous history of phobias were obtained. (d) The sampling method could have introduced selection bias in terms of socio-demographics. Although the intention was to conduct a national survey, the participants were stimulated to spread the form to other geographic regions. There were more answers from the south region of Brazil, where the investigators were located. (e) The participant pool only comprised a selected sample from the general Brazilian population, with the majority being females, with a high level of education. This fact could affect the generability of our findings. (f) It cannot be excluded that social desirability factors might have influenced participant responses to the questionnaire. (g) This study did not examine the stability of FCV-19S over time. Future research should therefore incorporate test-retest reliability measures into the design of their studies, although this could be interfered by the rapid evolution of the pandemic state. (h) The data were collected using a non-clinical sample, therefore, results may not be generalizable to a clinical setting.

Despite its limitations, the findings of this study can help professionals to deal with the mental health problems of the general population, generated by the SARS-CoV-2 pandemic. The use of the SCoV-2-FS can give rise to the assessment of the psychological impacts of the SARS-CoV-2 pandemic on individuals. Mental health professionals should investigate the relationships between the fear of SARSCoV-2 and panic attacks, obsessive-compulsive disorder, and stigma. Therefore, psychological interventions to alleviate the traumatic effects of SARS-CoV-2 using ScoV-2-FS should be designed (Shigemura et al., 2020). Future studies should also evaluate if individuals with underlying medical conditions associated with a higher risk of death from SARS-CoV-2 may experience increased levels of fear (Prezioso et al., 2020). The traumatic and stressful aspects of involvement in a pandemic also risks psychological harm to health workforce members, who experience increased burnout, compassion fatigue, and job dissatisfaction (Choi et al., 2020; Lu et al., 2020). Another distressful aspect, mainly for health workforce members, is the fast and voluminous quantity of scientific information produced by the SARS- CoV-2 pandemic, which would be difficult to follow and update for frontline professionals.

Excessive fear alongside social and economic consequences has the capacity to impair individuals' rational thinking behavior and may lead to mental health suffering and psychosocial challenges (Ahorsu e al., 2020; Xiang, 2020). Moreover, mental health issues (i.e., depression, stress, panic, distress, etc.) can in more extreme cases result in suicidal ideation, suicide attempts, and actual suicide occurrence 
(Mclntyre and Lee 2020). The SARS-CoV-2 pandemic has the potential to create a secondary crisis of psychological distress and mental health system spillover (Choi et al., 2020). Post-traumatic stress disorder (PTSD) is a common consequence of major disasters. Exceptional epidemic situations have also promoted PTSD in the past. PTSD is a secondary effect of the SARS-CoV-2 pandemic, both for the general population, patients, and healthcare workers. The identification of fear in the population may assist in the development and establishment of measures to prevent and control mental health disorders resulting from fear during and after the pandemic (Dutheil et al., 2020).

\section{Conclusions}

Overall, the results of the present study showed that the SCoV-2-FS has robust psychometric properties and can be used to assess fear during the SARS-CoV-2 pandemic in the general population. The SCoV$2 \mathrm{FS}$ will add to the investigation of psychological reactions to the pandemic, in association with other scales such as depression or anxiety scales.

The development of a valid instrument to identify and quantify fear gives the possibility to document this feeling during a unique period of human history. A specific reaction to a severe new situation in which humanity was not submitted in the contemporary age. This will enable the development of studies, not only on psychiatry and mental health as well as other interdisciplinary aspects such as history, conceptual art, sociology, and anthropology.

\section{Declarations}

\section{Data statement}

The data is available to access under request to the corresponding author after approval of the IRB.

\section{Statement on participant consent}

Participant signed an electronic statement consenting to participate and publish.

\section{Declaration of Competing Interest}

The authors declare no competing interests.

\section{References}

Ahorsu, D.K., Lin, C.Y., Imani, V., Saffari, M., Griffiths, M.D., Pakpour, A.H., 2020. The Fear of COVID-19 Scale: Development and Initial Validation. Int J Ment Health Ad.https://doi.org/10.1007/s11469-02000270-8

Alyami, M., Henning, M., Krägeloh, C.U., Alyami, H., 2020. Psychometric Evaluation of the Arabic Version of the Fear of COVID-19 Scale. Int J Ment Health Ad https://doi.org/10.1007/s11469-020-00316-x 
Barret, P., Kline, P., 1981. The observation to variable ratio in factor analyses. J Personal and Group Behavior. 2, 94-98.

Becker, S., Fuchs, X., Schakib-Ekbatan, K., Schweiker, M., 2020. What does "moderate pain" mean? Subgroups holding different conceptions of rating scales evaluate experimental pain differently. Eur $J$ Pain. 24, 625-638.

Bitan, D.T., Grossman-Giron, A., Bloch, Y., Mayer, Y., Shiffman, N., Mendlovic, S., 2020. Fear of COVID-19 scale: Psychometric characteristics, reliability and validity in the Israeli population. Psychiatr Res. 289, 113100

Choi, K.R., Heilemann, M.S.V., Fauer, A., Mead, M., 2020. A second pandemic: mental health spillover from the novel coronavirus (COVID-19). J Am Psychiatr Nurses Assoc. 27, 1078390320919803.

Doll, W.J., Xia, W., Torkzadeh, G.A., 1994. Confirmatory factor analysis of the end-user computing satisfaction instrument. MIS Quarterly. 18, 357-369.

Dong, E., Du, H., Gardner, L., 2020. An interactive web-based dashboard to track COVID-19 in real time. Lancet Infect Dis. 20, 533-534.

Dutheil, F., Mondillon, L., Navel, V., 2020. PTSD as the second tsunami of the SARS-Cov-2 pandemic. Psychol Med. 1-2. doi:10.1017/S0033291720001336

Ellul, M., Benjamin, L., Singh, B., Lant, S., Michael, B.D., Easton, A., Kneen, R., Defres, S., Sejvar, J., Solomon, T., 2020. Neurological Associations of COVID-19. Lancet Neurol. Forthcoming, Available at SSRN: https://ssrn.com/abstract=3589350 or http://dx.doi.org/10.2139/ssrn.3589350

Epstein, J.M., 2009. Modelling to contain pandemics. Nature, 460, 687.

Floyd, F.J., Widaman, K.F., 1995. Factor analysis in the development and refinement of clinical assessment instruments. Psychol Assess. 7, 286-299.

Garcia, R., 2017. Neurobiology of fear and specific phobias. Learn Mem. 24, 462-471.

Graham, J.M., 2006. Congeneric and (essentially) tau-equivalent estimates of score reliability - what they are and how to use them. Educ Psychol Meas. 66, 930-944. doi:10.1177/0013164406288165

Harper, C.A., Satchell, L.P., Fido, D., Latzman, R.D., 2020. Functional Fear Predicts Public Health Compliance in the COVID-19 Pandemic. Int J Ment Health Ad https://doi.org/10.1007/s11469-020-002815

Huang, C., Wang, Y., Li, X., Ren, L., Zhao, J., Zhang, L., Fan, G., Xu, J., Gu, X., Cheng, Z., Yu, T., Xia, J., Wei, Y., Wu, W., Xie, X., Yin, W., Li, H., Liu, M., Xiao, Y., Gao, H., Guo, L., Xie, J., Wang, G., Jiang, R., Gao, Z., Jin, Q., 
Wang, J., Cao, B., 2020. Clinical features of patients infected with 2019 novel coronavirus in Wuhan, China. Lancet. 395, 497-506.

Kline, R.B., 2015. Principles and practice of structural equation modeling (4th ed). New York: Guilford Publications.

Lu, W., Wang, H., Lin, Y., Li, L., 2020. Psychological status of medical workforce during the COVID-19 pandemic: A cross-sectional study. Psychiatry Res. 288, 112936. doi:10.1016/j.psychres.2020.112936

Mamun, M.A., Griffiths, M.D., 2020. First COVID-19 suicide case in Bangladesh due to fear of COVID-19 and xenophobia: possible suicide prevention strategies. Asian J Psychiatr. 51, 102073.

McIntyre, R.S., Lee, Y., 2020. Preventing suicide in the context of the COVID-19 pandemic. World Psychiatry.19, 250-251.

Netemeyer, R.G., Bearden, W.O., Sharma, S., 2003. Scaling procedures. Issues and applications. Thousand Oaks: Sage Publications.

Prezioso, C., Marcocci, M.E., Palamara, A.T., De Chiara, G., Pietropaolo, V., 2020. The "Three Italy" of the COVID-19 epidemic and the possible involvement of SARS-CoV-2 in triggering complications other than pneumonia. J NeuroVirol. 26, 311-323.

Rajkumar, R.P., 2020. COVID-19 and mental health: a review of the existing literature. Asian J Psychiatr.52, 102066

Riva, M.A., Benedetti, M., Cesana, G., 2014. Pandemic fear and literature:observations from Jack London's the Scarlet plague. Emerg Infect Dis. 20, 1753-1757.

Sakib, N., Bhuiyan, A.K.M.I., Hossain. S., Al Mamun, F., Hosen, I., Abdullah, A. H., Sarker, M. A., Mohiuddin, M. S., Rayhan, I., Hossain, M., Sikder, M. T., Gozal, D., Muhit, M., Islam, S., Griffiths, M. D., Pakpour, A. H., Mamun, M. A., 2020. Psychometric Validation of the Bangla Fear of COVID-19 Scale: Confirmatory Factor Analysis and Rasch Analysis. Int J Ment Health Ad. 11, 1-12. https://doi.org/10.1007/s11469-020-00289X

Satici, B., Gocet-Tekin, E., Deniz, M.E., Satici, SA., 2020. Adaptation of the Fear of COVID-19 Scale: It's Association with Psychological Distress and Life Satisfaction in Turkey. Int J Ment Health Ad. 8: 1-9. https://doi.org/10.1007/s11469-020-00294-0

Schimmenti, A., Billieux, J., Starcevic, V., 2020. The four horsemen of fear: an integrated model of understanding fear experiences during the COVID-19 pandemic. Clin Neuropsychiatry. 17, 41-45.

Shigemura, J., Ursano, R.J., Morganstein, J.C., Kurosawa, M., Benedek, D.M., 2020. Public responses to the novel 2019 coronavirus (2019-nCoV) in Japan: mental health consequences and target populations.

Psychiatry Clin Neurosci. 74, 281-282 
Slocum-Gori, S.L., Zumbo, B.D., 2011. Assessing the unidimensionality of psychological scales: using multiple criteria from factor analysis. Soc Indic Res. 102, 443-461.

Soraci, P., Ferrari, A., Abbiati, F.A., Del Fante, E., De Pace, R., Urso, A., Griffiths, M.D., 2020. Validation and Psychometric Evaluation of the Italian Version of the Fear of COVID-19 Scale. Int J Ment Health Ad. https://doi.org/10.1007/s11469-020-00277-1

Taubenberger, J.K., Morens, D.M., 2006. 1918 Influenza: the mother of all pandemics. Emerg Infect Dis. $12,15-22$.

Thakur,V., Jain, A., 2020. COVID 2019-Suicides: A global psychological pandemic. Brain Behav Immun. 23, S0889-1591(20)30643-7 https://doi.org/10.1016/j.bbi.2020.04.062

The Lancet, 2020. COVID-19 in Brazil: "So what?". Lancet. 395: 1461. 10. Merriam-Webster dictionary. https://www.merriam-webster.com/dictionary/fear. (accessed May 07, 2020)

Xiang, Y.T., 2020. Timely mental health care for the 2019 novel coronavirus outbreak is urgently needed. Lancet Psychiatry. 7, 228-229.

Zarocostas, J. (2020). How to fight an infodemic. The Lancet, 395(10225), 676

\section{Tables}

Table 1. English and Portuguese version of the SARS-CoV-2 Fear Scale (SCoV-2-FS)

\section{English version of the SARS-CoV-2 Fear Scale (SCOV-2-FS).}

1. If you need to go out on the street, how afraid would you be?

2. If you need to go to the market, how afraid would you be?

3. If you need to go to the pharmacy, how afraid would you be?

4. If you need to go to the hospital, how afraid would you be?

5. If you need to use an elevator, how afraid would you be?

6. Are you afraid of getting the new coronavirus?

7. Are you afraid of someone close to you getting the new coronavirus?

8. Are you afraid of having contact with other people?

9. Are you afraid to take public transport and get the new coronavirus?

10. Are you afraid of dying from complications caused by the new coronavirus?

11. Are you afraid of losing a loved one due to complications caused by the new coronavirus? 
The participants indicated their level of fear using a five-item Likert-type scale. Answers included a scale of 1 (no fear), 2 (mild), 3 (moderate), 4 (a lot), 5 (severe). The minimum possible score for each question was 1 , and the maximum score was 5 . A total score was calculated by adding up each item score (ranging from 11 to 55). The higher the score, the greater the fear of SARS-CoV-2.

\section{Portuguese version of the SARS-CoV-2 Fear Scale (SCoV-2-FS).}

1. Se você precisasse sair à rua, sentiria quanto medo?

2. Se você precisasse ir ao mercado, sentiria quanto medo?

3. Se você precisasse ir à farmácia, sentiria quanto medo?

4. Se você precisasse ir ao hospital, sentiria quanto medo?

5. Se você precisasse usar elevador, sentiria quanto medo?

6. Você tem medo de contrair o novo coronavírus?

7. Você tem medo de uma pessoa próxima contrair o novo coronavírus?

8. Você tem medo de ter contato com outras pessoas?

9. Você tem medo de andar de transporte público e contrair o novo coronavírus?

10. Você tem medo de morrer por complicações causadas pelo novo coronavírus?

11. Você tem medo de perder uma pessoa querida devido a complicações causadas pelo novo coronavírus?

Table 2. Descriptive analysis of the eleven items of the SARS-CoV-2 Fear Scale (SCoV-2-FS)

\begin{tabular}{|l|l|l|l|l|l|l|l|l|l|l|}
\hline items & Mean & SD & Variance & CV & $\begin{array}{c}95 \% \text { Confidence Interval } \\
(\text { CI })\end{array}$ & $\begin{array}{l}\text { Skewness } \\
\square 1\end{array}$ & $\begin{array}{l}\text { Kurtosis } \alpha 4 \\
\text { W }\end{array}$ & $\begin{array}{c}\text { Standardized factor } \\
\text { loading }\end{array}$ \\
\hline Total & 41.838 & 9.177 & 84.151 & 0.219 & $41.345^{*}-42.331$ & -0.850 & 0.312 & 0.942 & $<0.0001$ & \\
\hline Q 1 & 3.071 & 1.124 & 1.264 & 0.366 & $3.011-3.131$ & -0.102 & -0.665 & 0.916 & $<0.0001$ & 0.8866 \\
\hline Q 2 & 3.277 & 1.173 & 1.377 & 0.358 & $3.214-3.340$ & -0.274 & -0.754 & 0.910 & $<0.0001$ & 0.9182 \\
\hline Q 3 & 3.182 & 1.160 & 1.345 & 0.364 & $3.120-3.244$ & -0.164 & -0.770 & 0.915 & $<0.0001$ & 0.8947 \\
\hline Q 4 & 4.378 & 1.009 & 1.018 & 0.230 & $4.324-4.432$ & -1.746 & 2.455 & 0.662 & $<0.0001$ & 0.7145 \\
\hline Q 5 & 3.510 & 1.247 & 1.556 & 0.355 & $3.443-3.577$ & -0.435 & -0.805 & 0.886 & $<0.0001$ & 0.7265 \\
\hline Q 6 & 3.832 & 1.112 & 1.237 & 0.290 & $3.772-3.892$ & -0.603 & -0.561 & 0.857 & $<0.0001$ & 0.7153 \\
\hline Q 7 & 4.519 & 0.804 & 0.647 & 0.178 & $4.476-4.562$ & -1.835 & 3.213 & 0.643 & $<0.0001$ & 0.5329 \\
\hline Q 8 & 3.358 & 1.128 & 1.271 & 0.336 & $3.297-3.419$ & -0.349 & -0.535 & 0.906 & $<0.0001$ & 0.7602 \\
\hline Q 9 & 4.376 & 1.006 & 1.012 & 0.230 & $4.322-4.430$ & -1.774 & 2.580 & 0.663 & $<0.0001$ & 0.6912 \\
\hline Q10 & 3.733 & 1.302 & 1.694 & 0.349 & $3.663-3.803$ & -0.679 & -0.730 & 0.838 & $<0.0001$ & 0.6212 \\
\hline Q11 & 4.601 & 0.786 & 0.618 & 0.171 & $4.558-4.643$ & -2.289 & 5.331 & 0.569 & $<0.0001$ & 0.5226 \\
\hline
\end{tabular}

*Cut-off for severe fear

Shapiro-Wilk Test (W); 95\% critical value accepted range [0.998;1.000]

**It is assumed that the data is not normally distributed. 
Table 3. Reliability and Confirmatory factor analysis (CFA) statistics for the SARS-CoV-2 Fear Scale (SCoV-2-FS)

\begin{tabular}{|c|c|c|c|c|c|c|c|c|c|c|}
\hline & \multicolumn{5}{|c|}{ Reliability } & \multicolumn{5}{|c|}{ Confirmatory factor analysis (CFA) } \\
\hline & Cronbach $\alpha$ & Std. $\alpha$ & Guttman $\square 6$ & Average R & $\begin{array}{c}\text { McDonald's } \\
\omega\end{array}$ & Composite reliability & SRMR & CFI & GFI & NFI \\
\hline All items included & 0.930 & 0.930 & 0.941 & 0.548 & 0.950 & 0.927 & 0.079 & 0.850 & 0.786 & 0.847 \\
\hline Q1 excluded & 0.919 & 0.920 & 0.930 & 0.535 & 0.940 & 0.919 & 0.071 & 0.839 & 0.814 & 0.836 \\
\hline Q2 excluded & 0.917 & 0.919 & 0.928 & 0.532 & 0.940 & 0.918 & 0.066 & 0.857 & 0.845 & 0.853 \\
\hline Q3 excluded & 0.919 & 0.920 & 0.930 & 0.536 & 0.940 & 0.919 & 0.068 & 0.853 & 0.835 & 0.850 \\
\hline Q4 excluded & 0.923 & 0.924 & 0.936 & 0.550 & 0.950 & 0.920 & 0.086 & 0.846 & 0.784 & 0.843 \\
\hline Q5 excluded & 0.924 & 0.924 & 0.937 & 0.550 & 0.950 & 0.919 & 0.087 & 0.839 & 0.775 & 0.836 \\
\hline Q6 excluded & 0.922 & 0.923 & 0.933 & 0.544 & 0.950 & 0.918 & 0.081 & 0.870 & 0.816 & 0.867 \\
\hline Q7 excluded & 0.929 & 0.9293 & 0.934 & 0.568 & 0.950 & 0.926 & 0.062 & 0.905 & 0.838 & 0.901 \\
\hline Q8 excluded & 0.922 & 0.923 & 0.935 & 0.544 & 0.950 & 0.917 & 0.088 & 0.839 & 0.780 & 0.836 \\
\hline Q9 excluded & 0.923 & 0.924 & 0.936 & 0.548 & 0.950 & 0.919 & 0.083 & 0.858 & 0.807 & 0.855 \\
\hline Q10 excluded & 0.927 & 0.927 & 0.936 & 0.558 & 0.950 & 0.923 & 0.080 & 0.870 & 0.809 & 0.867 \\
\hline Q11 excluded & 0.929 & 0.929 & 0.934 & 0.568 & 0.950 & 0.926 & 0.060 & 0.904 & 0.843 & 0.900 \\
\hline
\end{tabular}

Confirmatory factor analysis (CFA): standardized root mean square residual (SRMR); comparative fit index (CFI); Goodness of fit index (GFI); normed of fit index (NFI).

Table 4. Standardized variance/covariance matrix (Correlation matrix) between the eleven items of the SCoV-2-FS

\begin{tabular}{|c|c|c|c|c|c|c|c|c|c|c|c|}
\hline & e1 1 & Q2 & Q3 & Q4 & Q5 & Q6 & Q7 & Q8 & Q9 & Q10 & Q11 \\
\hline & $1 * * *$ & 0.84 & 70.81 & 90.58 & 90.63 & 0.628 & 80.416 & 50.668 & 0.547 & 0.529 & 0.392 \\
\hline & $2<0$ & jor & 0.876 & 60.63 & 0.647 & 0.601 & 0.429 & 0.677 & 0.598 & 0.516 & 0.416 \\
\hline$\Omega_{2}$ & $\beta<0.00$ & $0 \nless 0$. & $01 * * * *$ & 0.62 & 0.62 & 0.582 & 20.42 & 0.64 & $0.56 \beta$ & \$ 0.487 & 0.40 \\
\hline 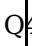 & $4<0.00$ & $0 \nless 0$ & $\leqslant 0.0$ & 0 10**** & 0.57 & 0.542 & 0.400 & 0.550 & $0.61 \beta$ & 0.475 & 0.430 \\
\hline $\mathrm{Q}$ & $5<0.00$ & 010 & 10 & $0 \leqslant 0$ & **** & 0.54 & 0.39 & 30.57 & $0.56 \beta$ & 0.468 & 0.38 \\
\hline C & $6<0.00$ & $k 0$ & $=0$. & $k 0.0$ & $k 0.00$ & $0 * * * *$ & 0.568 & 80.57 & 0.55 & 0.632 & 0.466 \\
\hline Q & $7-0$ & $0 \nless 0.0$ & -0 & 10 & 10 & $0 \mathrm{~K} 0$. & F**** & 0.442 & 0.45 & 0.388 & 0.685 \\
\hline & $8<0.00$ & $0 \leqslant 0$. & $\leqslant 0.0$ & $01 \leqslant 0.0$ & $0 \mathrm{k} 0.0$ & $01<0.0$ & $0 \mathrm{~K} 0.00$ & $01 * * * *$ & 0.609 & 0.521 & 0.435 \\
\hline $\mathrm{Q}$ & $9<0$ & 10 & 40 & $1 \times 0$ & $k 0$ & $1<0$ & $0 K 0$ & $0<0$. & 0 0*** & 0.511 & 0.477 \\
\hline & $1<0.00$ & $0 \nless 0$. & $1<0$. & 100 . & K 0 . & $k 0$. & $k 0$ & 010 & $0 \leqslant 0$ & $01 * * * *$ & 0.505 \\
\hline & & & & & & & & & & & \\
\hline
\end{tabular}

Upper diagonal part contains correlation coefficient estimates; lower diagonal part contains corresponding p-values. There was a positive relationship between all items; minimum and maximum were indicated in gray cells.

\section{Figures}




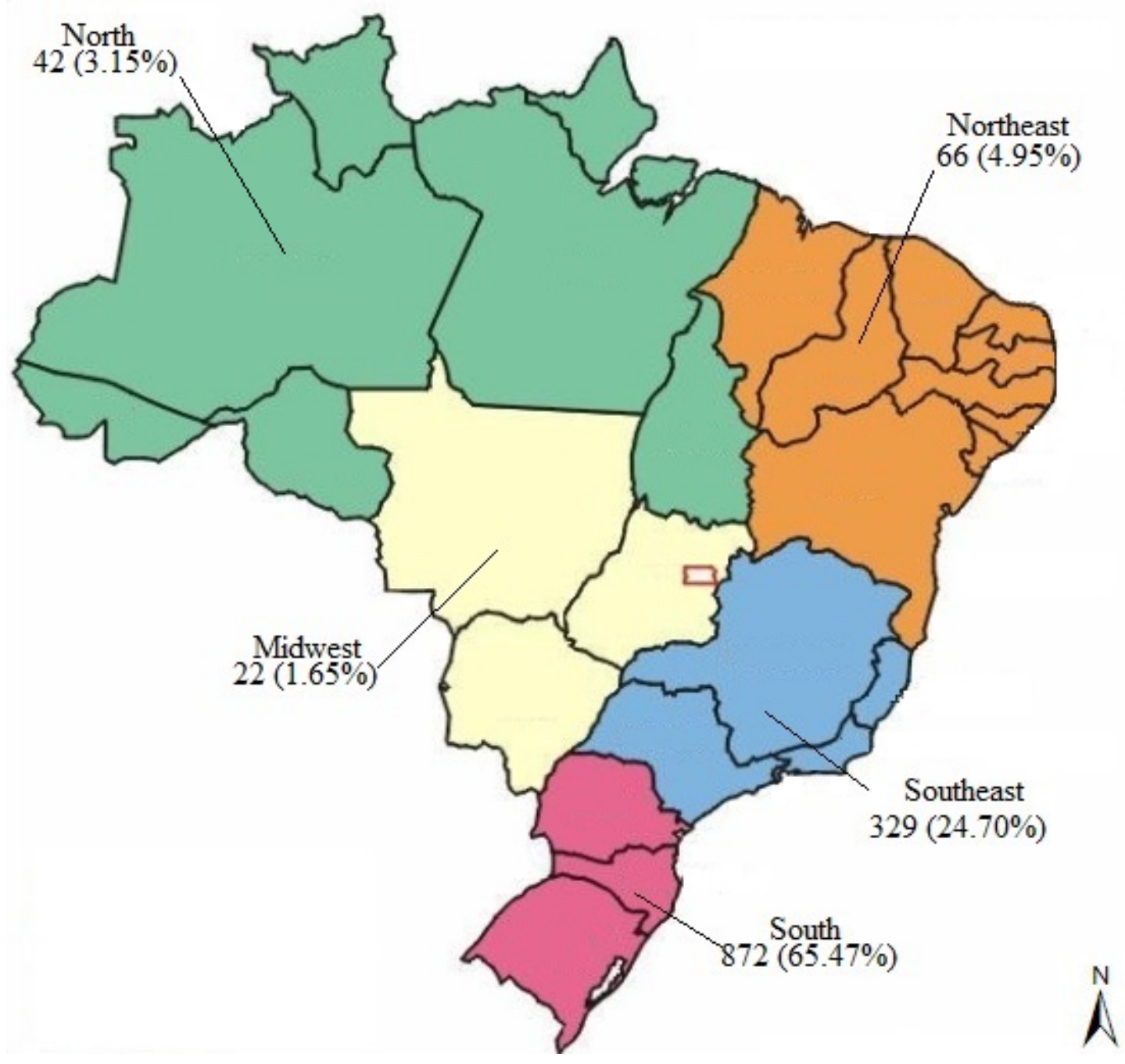

Figure 1

Distribution of received forms according to Brazil geographic regions (Instituto Brasileiro de Geografia e Estatistica - IBGE, https://www.ibge.gov.br): North (green); Northeast (orange); Midwest (yellow); Southeast (blue); South (pink). 

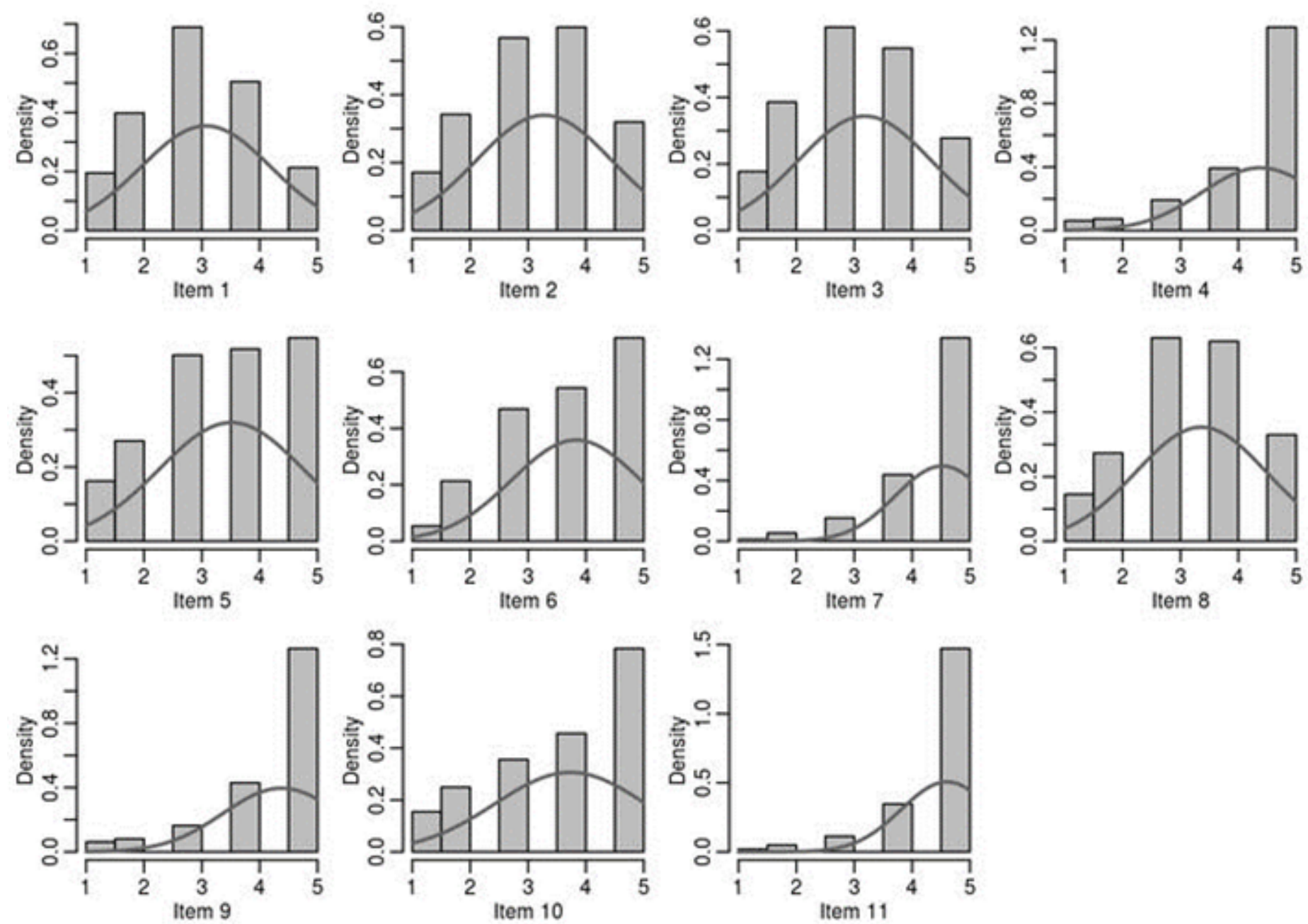

Figure 2

Histograms of the 11 SCoV-2-FS items, the black line refers to the normal distribution curve

\section{Supplementary Files}

This is a list of supplementary files associated with this preprint. Click to download.

- Graphicalabstract2.jpg

- SuppIFigure1.JPG 